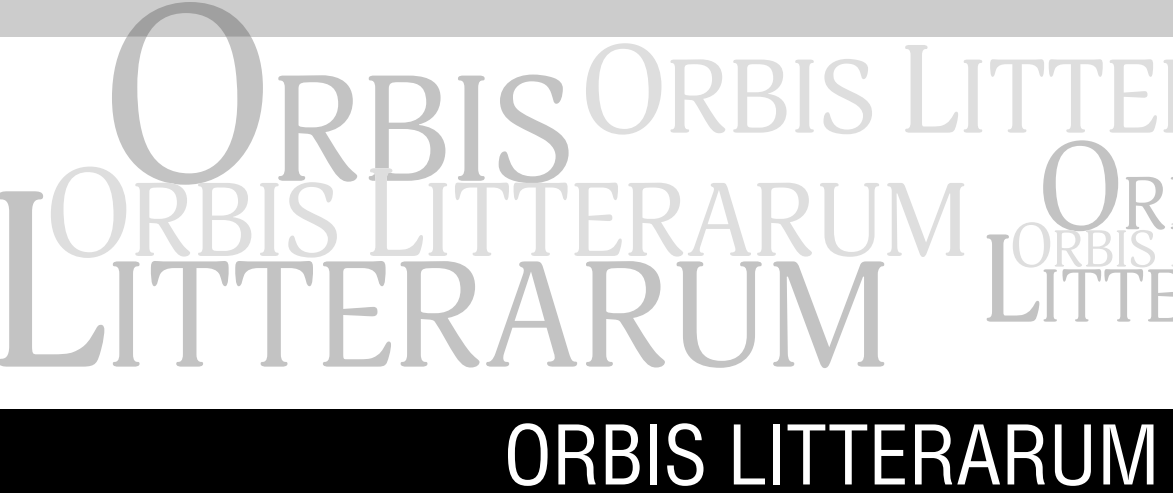

УдК 130.2

ББК 71.0

\section{H. АСТАФЬЕВA}

\section{НАУЧНО-ИЗДАТЕЛЬСКИЙ ПРОЕКТ КАК ОТКРЫТАЯ КОММУНИКАЦИЯ: М.С. КАГАН В ОТЕЧЕСТВЕННОМ ГУМАНИТАРНОМ ЗНАНИИ}

\section{Ольга Николаевна Астафьева,}

Российская академия народного хозяйства и государственной службы при Президенте РФ, Институт государственной службы и управления, Научно-образовательный центр «Гражданское общество и социальные коммуникации», директор, доктор фиилософрских наук, просрессор e-mail: onastafieva@mail.ru

Вернадского просп., д. 82, стр. 1, Москва, 119571, Россия

В основе статьи - размышления автора, выступившего ведущим презентации, посвященной значительному событию в культурной и научной жизни страны, - выходу в свет семитомного издания избранных трудов известного философа и культуролога Моисея Самойловича Кагана. Автор анализирует вклад М.С. Кагана в развитие отечественных наук о культуре, раскрывая тематическую и методологическую направленность его работ, формирующих содержательное ядро каждого из изданных томов, высоко оценивая значение исследователя для развития эстетики, искусствоведения, философии (и философии культуры в том числе), а также истории культуры и культурологии. Особый интерес представляют приводимые в тексте идеи и высказывания участников презентации - признанных исследователей, лично знавших М.С. Кагана: В.М. Межуева, И.В. Кондакова, Н.А. Хренова, О.Н. Астафьевой, И.М. Быховской, М.М. Шибаевой, А.Б. Ройфе и других, которыми отмечается значимость для гуманитарной науки издания избранных работ М.С. Кагана. Участниками презентации подчеркивается роль заслуженного деятеля науки Российской Федерации - почетного профессора Санкт-Петербургского государственного университета М.С. Кагана, которому 18 мая 2016 г. исполнилось бы 95 лет со дня рождения - в формировании одной из отечественных научных школ о культуре, успешно развивающейся и в настоящее время.

Ключевые слова: М.С. Каган, науки о культуре, философия культуры, культурология, гуманитарное знание, системный подход к культуре, системно-синергетический подход, избранные труды М.С. Кагана.

Для цитирования: Астафьева О.Н. Научно-издательский проект как открытая коммуникация: М.С. Каган в отечественном гуманитарном знании // Обсерватория культуры. 2016. Т. 1. № 2. C. $234-239$. 


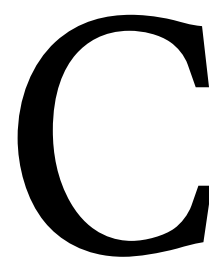

ообщение о том, что в авторском зале 17-й Международной ярмарки интеллектуальной литературы NON/FICTION в Центральном доме художника в Москве издательский дом «Петрополис» представит семитомное издание избранных сочинений выдающегося ученого и философа М.С. Кагана ${ }^{1}$, вызвало неподдельный интерес в научных кругах России. Событие оказалось значимым не только как презентация известных работ отечественного исследователя, получивших широкое признание в философии и науке, но и как редчайший факт сегодняшнего дня - появление на свет многотомного издания выдающегося эстетика, философа, культуролога, своими идеями и концепциями внесшего значительный вклад в развитие современного знания.

Чем больше проходит времени с того момента, как М.С. Каган ушел из жизни, тем больше внимания уделяется его трудам, тем очевиднее становятся масштабы его научной деятельности, последовательно «захватывавшей» в орбиту своего таланта все новые и новые области познания. Обладая уникальным чутьем на новое, особой творческой интуицией, ведущей его к

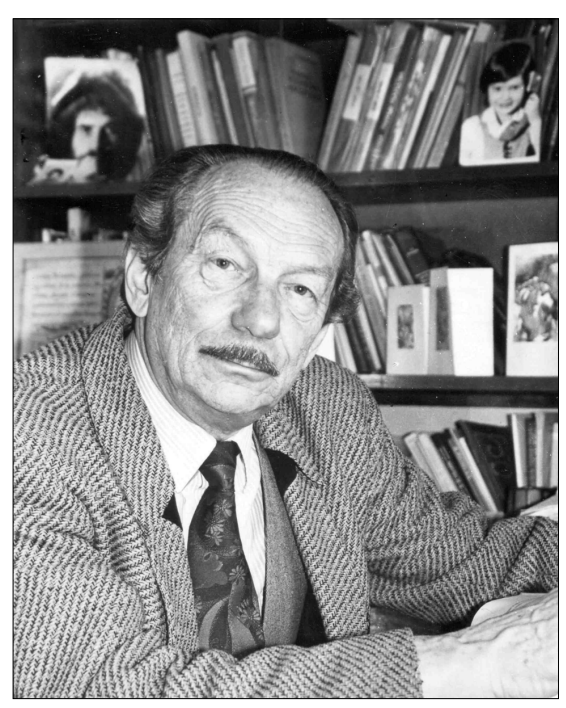

M.C. Каган философской мысли и культурологической науки в течение последних 50 лет.

«Издание избранных работ заняло около 10 лет, - рассказала на презентации генеральный директор издательского дома “Петрополис" Е.Г. Павлова, - ведь чтобы систематизировать материал и не упустить ни одной работы, наиболее значимой для наших современников, потребовалась помощь многих специалистов, его коллег и его семьи. В итоге, как нам представляется, издание всесторонне охватывает творчество Моисея Самойловича Кагана, раскрывая его перед нашими современниками и как выдающегося ученого и философа, и как личность, чья гражданская позиция всегда вызывала глубокое уважение. В издательском проекте - от составления плана, выбора книг и статей для каждого из томов до утверждения макета первого тома Моисей Самойлович участвовал лично, посвятив этому последние месяцы своей жизни».

Семь книг, вобравших избранные труды М.С. Кагана, охватывают разные научные направления, предметные и междисциплинарные области знания, раскрывают проблемы методологии (Т. I), теоретические проблемы философии (Т. II), проблемы теории культуры (Т. III), теоретического искусствознания и эстетики (T. IV, T. V), истории мироавторским открытиям, М.С. Каган бросал вызов устаревшему и не отвечающему современной ситуации знанию, тем самым сумев сказать свое собственное слово в эстетике и искусствознании, философии культуры и культурологии, междисциплинарных исследованиях.

Глубина постановки актуальных, и для теории, и для практики, проблем, инновационность предлагаемых методологических решений, особый исследовательский дар и творческая самоотдача, энциклопедичность ума и желание разобраться в сложнейших вопросах бытия человека в культуре в полной мере нашли свое отражение в изданных в разные годы трудах - «Морфология искусства» (1972), «Философия культуры» (1996), «Эстетика как философская наука» (1997), «Философская теория ценностей» (1997), «Се Человек» (2002), «Град Петров» (1996, 1-е изд.; 2006, 2-е изд.), «Метаморфозы бытия и небытия. Онтология в системно-синергетическом осмыслении» (2006) и многих других, где выкристаллизовывались идеи в той или иной степени воплощенные и в масштабном произведении - «Введение в историю мировой культуры» (2001-2003). Работы М.С. Кагана стали заметными вехами на определенных этапах становления вой культуры и философско-эстетической мысли (T. VI). В том седьмой включены труды, интервью, обращения ученого, активно откликающегося на актуальные социально-культурные вопросы [1-8].

Перед участниками презентации «Избранных трудов...» стояла сложнейшая задача - раскрыть мир идей ученого, представленный в этом многотомном издании ${ }^{2}$.

Давая оценку времени, когда имя М.С. Кагана прочно вошло в отечественную гуманитарную науку (1960-1970-е гг.), известный философ культуры В.М. Межуев подчеркнул, что лучше всех о себе и людях своего времени М.С. Каган рассказал в одной из своих книг [10, с. 403-642]. «Хотя нас с ним многое различает - принадлежность к разным поколениям и разный социальный опыт, расхождение в подходах к пониманию культуры и стиль гуманитарного мышления, выявить значение М.С. Кагана - как ученого, и как личности, - считает B.M. Межуев, - невозможно без учета социокультурного контекста, в котором создавал свои концепции М.С. Каган. Только тогда можно понять и только тогда становится очевидным, как его мысль “выкарабкивалась” из тисков догматики “теории от- 
ражения”, идя от эстетики - к теории деятельности. Одновременно в это же время Э.В. Ильенков также искал возможность преодоления устаревших идей, но шел по иному пути - от теории познания».

«Когда люди будут изучать нашу эпоху, то они смогут это сделать по книгам Кагана. Его работы не всегда принимались однозначно, какие-то идеи вызывали непонимание, однако именно в процессе доказательств складывалась научная школа Моисея Самойловича Кагана. Сегодня любят изображать советский период как пропуск в сознании людей, как пропуск мысли, однако это далеко не так, поскольку в духовном плане советская школа была очень интересна по степени накала проблематики, страстей и дискуссий. Именно это время стало временем рождения социологии и культурологии. А в отечественной теории культуры сложилось несколько научных школ, связанных с конкретными именами: школа Э.С. Маркаряна, который шел к культуре от социологии; школа В.С. Библера, пытавшегося соединить идеи M.М. Бахтина о диалоге культур с гегелевской диалектикой; школа Ю.М. Лотмана - семиотическая. И была школа М.С. Кагана, где основным стал системный подход к культуре. Более полного охвата целостности культуры, чем у М.С Кагана, я не знаю. Никто не превзошел его в этом», - считает В.М. Межуев. Как оказалось, потребовалось значительное время для переосмысления прежних парадигм и принятия понимания культуры как сложной системы другими исследователями.

Многообразие идей и мыслей, в котором проявилось умение концептуализации и теоретического моделирования М.С. Кагана, опровергает какие-либо утверждения о неспособности носителей одной системы взглядов понимать и принимать как «старое», так и «новое» знание. Талант М.С. Кагана - в преодолении риска полного «разрыва», в способности продвигаться к новой парадигме через принятие языка объяснения, произрастающего из ранее созданной и раскрытой концептуальной системы. Так в течение почти двух последних десятилетий его научной творческой жизни совершался переход с обоснованного и концептуализированного системного подхода в гуманитарном знании к системно-синергетическому подходу: переход от одного уровня рациональности к другому уровню - новой рациональности.

Осознание важности системного подхода и потребности в его проективной реализации на сферу искусства способствовало осуществлению задуманного не только в создании М.С. Каганом научной монографии «Морфология искусства», но и в разработке программы «гуманитаризации» системного мышления в целом. Мы можем судить об этом по многочисленным статьям, включенным в раздел «Становление методологии современного гуманитарного исследования» первого тома: «Системность и целостность», «Наследие Л. фон Берталанфи и проблемы применения системного подхода в сфере гуманитарного знания» и другим [1, с. 2-165]. Предлагаемая М.С. Каганом концепция системного подхода не принималась однозначно и «адаптировалась» к языку философского описания в течение длительного времени.

Динамичность мыслительного процесса М.С. Кагана привела его к идее расширения гуманитарной парадигмы - более эффективному, по мысли М.С. Кагана, аналитическому системно-синергетическому методу, который позволил не только провести типологию антропо-социо-культурных систем на новых основаниях [11, с. 212-227], но и далее применить этот метод к изучению истории культуры, раскрыть сложность мира культуры. Во втором разделе «Системный подход и синергетика» первого тома опубликованы статьи, в которых раскрывается суть методологии синергетики, вызвавшей не меньше дискуссий, чем десятилетия назад - системного подхода («Синергетическая парадигма - диалектика общего и особенного в методологии познания разных форм бытия», «О синергетическом подходе к построению современной онтологии» и др. [1, с. 166-294]).

Осмысливая значение разработанного методологического инструментария для исследований теории и истории культуры, которые М.С. Каган провел в последнее десятилетие своей жизни, можно говорить о том, что он занял особое место в разработке социокультурной синергетики [12, с. $470-$ $481 ; 13$, с. 255-278]. К этой теме неоднократно будут возвращаться исследователи, поскольку, на наш взгляд, сегодня сложилась та ситуация в научном познании, когда оценка предлагаемой методологической системы дается не на основе перспектив изменения в объяснительных моделях мира культуры, а исходя из тиражируемых схематизаций. То есть «опирается на не очень явные представления о “сущности” описываемой программы, оставляя вне поля зрения некоторые важные смыслы, содержащие в ней, но выраженные косвенно, неявно» [14, с. 214]. Тем не менее, это не мешает другим исследователям, обращающимся к методу, выявить предполагаемое содержание вполне успешно, когда оно становится актуальным [14, с. 214].

Когда в 2005 г. в серии научно-методологических семинаров «Культура и культурная политика» в Российской академии государственной службы при Президенте РФ (ныне - РАНХиГС) состоялась масштабная конференция, посвященная синергетической концепции М.С. Кагана, на которой обсуждалось «Введение в историю мировой культуры» [15], одним из первых выступающих в дискуссии был профессор Н.А. Хренов. Не случайно, по прошествии десяти лет на нынешней презентации он вспомнил об этом событии и начал свою оценку издания с характеристики научного стиля и мышления исследователя, который каждый раз по-новому раскрывался 
для него на протяжении всего времени их знакомства. При этом, заметил Н.А. Хренов, стиль выступления и статей ученого всегда отличался методологической глубиной, логикой и продуманностью.

«Мы заново возвращаемся к мыслям М.С. Кагана и, перечитывая их, пытаемся еще раз проанализировать и понять, что держало внимание наших современников не одно десятилетие. Мне приходилось вступать в спор с М.С. Каганом относительно недооценки роли Востока в истории мировой культуры и, мне кажется, он отнесся внимательно к моим критическим замечаниям. <...> Очень жаль, - подчеркнул Н.А. Хренов, - что не было возможности записать великолепные по содержанию и драматургии выступления и лекции петербургского профессора».

В жизни М.С. Кагана присутствовала особая «волевая напряженность» по продвижению новых идей, которые, по выражению самого исследователя, всегда были для него преодолением «примитивного рационализма и однобокого гносеологизма». Отсюда горькая нота трагизма и недопонимания, которая звучала в выступлениях М.С. Кагана, считает профессор И.В. Кондаков, а ведь большинством своих трудов он закладывал новые методологические решения сложнейших междисциплинарных проблем. «Несомненно, что включив эстетику в культурологию и философию культуры как составную часть, М.С. Каган кардинальным образом изменил гуманитарное знание. Когда все различные аспекты культуры были сведены им в одной точке, сложилось системное видение культуры, и это огромная заслуга М. Кагана перед всей нашей гуманитарной наукой. Согласитесь, издание собрания его сочинений - также очень важный факт. Семь томов трудов М.С. Кагана дополнят единичные известные издания наших классиков Вяч. Иванова, Д.С. Лихачева, Ю.М. Лотмана».

«Избранные труды М.С. Кагана - это труды именно классика культурологии и отечественной гуманитарной науки в целом, - подчеркнула профессор И.М. Быховская, - потому что им задана модель изучения культуры; можно не соглашаться с какимито положениями теоретических построений, но без его работ невозможно понять феномен культуры и его многоаспектность. Это тот исследователь, труды которого позволяют сформировать гуманитарный стиль мышления у любого человека, независимо от его профессиональной принадлежности; наконец, это педагог, чьи работы востребованы в силу ответственности автора за будущие поколения».

На презентации была дана всесторонняя оценка и других сторон творчества М.С. Кагана: о его искусствоведческих изысканиях и встречах с удивительной «артистической индивидуальностью», человеком безукоризненного художественного и эстетического вкуса, М.С. Каганом, который «либо наедине, либо с актерами» умел дать точную оцен- ку любому театральному спектаклю известнейших режиссеров современности, своими впечатлениями поделились профессор М.М. Шибаева и другие. В обсуждении приняли участие ученики и коллеги ученого (А. Ройфе, Л. Гозман, М. Щадрин и др.), его сын Михаил Каган, члены редакции журнала «Обсерватория культуры», научные работники, преподаватели и студенты вузов Москвы.

В мае 2016 г. М.С. Кагану - одному из основоположников отечественной культурологии, теории искусства и эстетики, философу культуры исполнилось бы 95 лет. Все присутствующие единодушно поддержали предложение посвятить этому событию, помимо ежегодно проводимых Кагановских научных чтений, круглый стол, продолжив обсуждение идей, с которыми теперь можно ознакомиться, благодаря выходу в свет семитомного издания избранных трудов ученого, перекидывающего мостик для будущих исследований культуры.

На наш взгляд, особенностью коммуникативной модели М.С. Кагана - этого смелого инициатора методологических изменений, открывающего мир своих идей для научного сообщества, - является не «поиск ради поиска» максимально новаторского решения, а построение объяснительного текста усложняющегося мира культуры. Его последовательная познавательная деятельность в области теории и методологии исследований культуры объединена общим внутренним вектором - оформить в языке свои представления, свободные от давления устоявшихся познавательных парадигм, при этом «не изживая» марксизм из своих представлений, сторонником которого он являлся, но сохраняя его базовые основания. Это позволяло ученому быть свободным от возможных обвинений в «иррационализме», устраняло любые «подозрения» в необъективности его теоретических представлений.

Открытость будущим поколениям и ответственность перед ними звучит почти в каждой работе М.С. Кагана: его волновало и состояние экологии, и давление глобализации, и угрозы генной инженерии, и разрастающийся терроризм - поэтому достижение единства человечества на основе диалога разных культур виделось им как цель развития.

Общеизвестно, что тексты каждого исследователя открывают читателю его трудов мир мыслей и представлений автора. Таковы научные и философские работы М.С. Кагана, приглашающие к открытой научной коммуникации, в которую верил ученый, оставляя потомкам свое собрание сочинений. Постижение их глубины, по сути, бесконечно и ждет своих новых исследователей.

\section{примечания}

127 ноября 2015 г. в рамках работы 17-й Международной ярмарки интеллектуальной литературы NON/FICTION в Центральном доме художника в 
Москве состоялась презентация семитомного издания избранных сочинений выдающегося ученого и философа М.С. Кагана (1921-2006), в организации которой приняли участие издательский дом «Петрополис», Московское научно-образовательное культурологическое общество, Институт государственной службы и управления РАНХигС, агентство «ИнтерМедиаКом», журнал «Обсерватория культуры», а также коллеги, друзья и родные исследователя. В статье используются материалы стенограммы выступлений, прозвучавших на презентации.

2 Издательским домом «Петрополис» в 2011 г. к 90-летию со дня рождения М.С. Кагана опубликован том восьмой, дополняющий издание избранных трудов. В него включены воспоминания учеников, коллег и друзей, научные статьи о творчестве М.С. Кагана [9].

\section{Список источников}

1. Каган М.С. Избранные труды в 7 томах. Санкт-Петербург : ИД «Петрополис», 2006. Т. І. Проблемы методологии. $356 \mathrm{c.}$

2. Каган М.С. Избранные труды в 7 томах. Санкт-Петербург : ИД «Петрополис», 2006. Т. II. Теоретические проблемы философии. 660 с.

3. Каган М.С. Избранные труды в 7 томах. Санкт-Петербург : ИД «Петрополис», 2007. Т. III. Труды по проблемам теории культуры. 756 с.

4. Каган М.С. Избранные труды в 7 томах. Санкт-Петербург : ИД «Петрополис», 2012. T. IV. Проблемы теоретического искусствознания и эстетики. 636 с.

5. Каган М.С. Избранные труды в 7 томах. Санкт-Петербург : ИД «Петрополис», 2008. Т. V. Кн. 1. Проблемы теоретического искусствознания и эстетики. 408 с.

6. Каган M.С. Избранные труды в 7 томах. Санкт-Петербург : ИД «Петрополис», 2008. Т. V. Кн. 2. Проблемы теоретического искусствознания и эстетики. 897 с.
7. Каган М.С. Избранные труды в 7 томах. Санкт-Петербург : ИД «Петрополис», 2013. T. VI. Из истории мировой культуры и философско-эстетической мысли. 692 с.

8. Каган М.С. Избранные труды в 7 томах. Санкт-Петербург : ИД «Петрополис», 2013. T. VII. Последние труды, интервью, обращения. 756 с.

9. Каган М.С. Избранные труды в 7 томах. Санкт-Петербург : ИД «Петрополис», 2011. T. VIII. Дополнительный. Моисей Каган. Во времени и в пространстве. $450 \mathrm{c}$.

10. Каган М.С. О времени, о людях и о себе // Избранные труды в 7 томах. Санкт-Петербург : ИД «Петрополис», 2013. T. VII. Последние труды, интервью, обращения. С. 403-642.

11. Каган М.С. Формирование личности как синергетический процесс // Синергетическая парадигма. Человек и общество в условиях нестабильности / отв. ред. О.Н. Астафьева. Москва : Прогресс-Традиция, 2003. T. III. C. $212-227$.

12. Астафьева О.Н. Социокультурная синергетика: предметная область, история и перспективы // Синергетическая парадигма. Синергетика образования / отв. ред. В.Г. Буданов. Москва : Прогресс-Традиция, 2007. С. $470-481$.

13. Астафьева О.Н. Мир и личность М.С. Кагана: путь к системно-синергетическому пониманию культуры // Каган М.С. Избранные труды в 7 томах. Санкт-Петербург : ИД «Петрополис», 2013. T. VIII. Дополнительный. Последние труды, интервью, обращения. C. $255-278$.

14. Гусев С.С. Метафизика текста: коммуникативная логика. Санкт-Петербург : ИЦ «Гуманитарная академия», 2008. 352 с.

15. Каган М.С. Введение в историю мировой культуры : в 2-х кн. Кн. 1. Санкт-Петербург : ООО Издательство «Петрополис», 2001. 383 с. ; Кн. 2. Санкт-Петербург : ООО Издательство «Петрополис», 2003. 320 с.

\section{O.N. ASTAFIEVA}

\section{SCIENTIFIC PUBLISHING PROJECT AS AN OPEN COMMUNICATION: M.S. KAGAN IN THE RUSSIAN HUMANITIES}

The article introduces the thoughts of the author, who was the presenter of the ceremony dedicated to a considerable event in the cultural and scientific life of the country - the publication of the seven-volume edition of the selected works of the philosopher and culturologist Moisey Samoilovich Kagan. The author analyzes the contribution of M.S. Kagan in the development of national cultural sciences, reveals the thematic and methodological orientation of his works which form an informative core of each of the published volumes, and highly praises the researcher's importance for the development of aesthetics, art history, philosophy (and philosophy of culture, in particular), as well as the history of culture and culturology. Given in the article, the ideas and opinions of the participants of the presentation are of particular interest. Among the participants, there are the well-known researchers acquainted with M.S. Kagan: V.M. Mezhuev, I.V. Kondakov, N.A. Khrenov, O.N. Astafieva, I.M. Bykhovskaya, M.M. Shibaeva, A.B. Roife and others, who emphasize the importance for the humanities of the publication of M.S. Kagan's selected works. The participants of the presentation highlight the role of this Honored Scientist of the Russian Federation, Honorary Professor of the Saint Petersburg State University, M.S. Kagan, who would become 95 years old on the 18th May 2016, in the formation 
of one of the Russian research cultural schools, successfully developing in our days.

Key words: M.S. Kagan, cultural sciences, culture, philosophy of culture, the humanities, system approach in culture, system-synergetic approach, selected works of M.S. Kagan.

Citation: Astafieva O.N. Scientific Publishing Project as an Open Communication: M.S. Kagan in the Russian Humanities, Observatory of Culture, 2016, vol. 1, no. 2, pp. 234-239.

\section{About author \\ Olga Nikolayevna Astafieva,}

Russian Presidential Academy of National Economy and Public Administration,

Institute of Public Administration and Management, Research Educational Center "Civil Society and Social Communications”, Director,

Doctor of Philosophical Sciences, Professor

e-mail:onastafieva@mail.ru

82-1 Vernadsky Av.,

Moscow, 119571, Russia

\section{References}

1. Kagan M.S. Izbrannye trudy $v 7$ tomakh [Selected Works in 7 vol.]. St. Petersburg, Petropolis Publ., 2006, vol. I: Problemy metodologii, $356 \mathrm{p}$.

2. Kagan M.S. Izbrannye trudy $v 7$ tomakh [Selected Works in 7 vol.]. St. Petersburg, Petropolis Publ., 2006, vol. II: Teoreticheskie problemy filosofii, $660 \mathrm{p}$.

3. Kagan M.S. Izbrannye trudy $v 7$ tomakh [Selected Works in 7 vol.]. St. Petersburg, Petropolis Publ., 2007, vol. III: Trudy po problemam teorii kul'tury, $756 \mathrm{p}$.

4. Kagan M.S. Izbrannye trudy $v 7$ tomakh [Selected Works in 7 vol.]. St. Petersburg, Petropolis Publ., 2012, vol. IV: Problemy teoreticheskogo iskusstvoznaniya i estetiki, $636 \mathrm{p}$.

5. Kagan M.S. Izbrannye trudy $v 7$ tomakh [Selected Works in 7 vol.]. St. Petersburg, Petropolis Publ., 2008, vol. V, book 1: Problemy teoreticheskogo iskusstvoznaniya i estetiki, $408 \mathrm{p}$.
6. Kagan M.S. Izbrannye trudy $v 7$ tomakh [Selected Works in 7 vol.]. St. Petersburg, Petropolis Publ., 2008, vol. V, book 2: Problemy teoreticheskogo iskusstvoznaniya i estetiki, $897 \mathrm{p}$.

7. Kagan M.S. Izbrannye trudy $v 7$ tomakh [Selected Works in 7 vol.]. Vol. VI: Iz istorii mirovoi kul'tury ifilosofsko-esteticheskoi mysli. St. Petersburg, Petropolis Publ., 2013. $692 \mathrm{p}$.

8. Kagan M.S. Izbrannye trudy $v 7$ tomakh [Selected Works in 7 vol.]. St. Petersburg, Petropolis Publ., 2013, vol. VII: Poslednie trudy, interv'yu, obrashcheniya, $756 \mathrm{p}$.

9. Kagan M.S. Izbrannye trudy $v 7$ tomakh [Selected Works in 7 vol.]. St. Petersburg, Petropolis Publ., 2011, vol. VIII: Dopolnitel'nyi. Moisei Kagan. Vo vremeni i v prostranstve, $450 \mathrm{p}$.

10. Kagan M.S. O vremeni, o lyudyakh i o sebe, Izbrannye trudy $v 7$ tomakh [Selected Works in 7 vol.]. St. Petersburg, Petropolis Publ., 2013, vol. VII: Poslednie trudy, interv'yu, obrashcheniya, pp. 403-642.

11. Kagan M.S. Formirovanie lichnosti kak sinergeticheskii protsess. Sinergeticheskaya paradigma. Chelovek i obshchestvo v usloviyakh nestabil'nosti. Moscow, ProgressTraditsiya Publ., 2003, vol. III, pp. 212-227.

12. Astaf'eva O.N. Sotsiokul'turnaya sinergetika: predmetnaya oblast', istoriya i perspektivy. Sinergeticheskaya paradigma. Sinergetika obrazovaniya. Moscow, Progress-Traditsiya Publ., 2007, pp. 470-481.

13. Astaf'eva O.N. Mir i lichnost' M.S. Kagana: put' k sistemno-sinergeticheskomu ponimaniyu kul'tury, $\mathrm{Ka}$ gan M.S. Izbrannye trudy $v 7$ tomakh [Kagan M.S. Selected Works in 7 vol.]. St. Petersburg, Petropolis Publ., 2013, vol. VIII: Dopolnitel'nyi. Poslednie trudy, interv'yu, obrashcheniya. pp. 255-278.

14. Gusev S.S. Metafizika teksta: kommunikativnaya logika. St. Petersburg, Gumanitarnaya akademiya Publ., 2008. $352 \mathrm{p}$.

15. Kagan M.S. Vvedenie $v$ istoriyu mirovoi kul'tury (in 2 books). St. Petersburg, Petropolis Publ., 2001, book 1, 383 p.; St. Petersburg, Petropolis Publ., 2003, book 2, $320 \mathrm{p}$. 